\title{
Design and Stress Analysis of Metalhydride Pressure Vessel
}

\author{
Lukáš Tóth ${ }^{1, *}$, Filip Duda ${ }^{1}$, Natália Jasmínská ${ }^{1}$, Tomáš Brestovič ${ }^{1}$ \\ Technical University of Košice, Faculty of mechanical engineering, Department of Power Engineering, Vysokoškolská 4, 04200 Košice, Slovakia
}

Abstract: The article describes the design and strength calculation of a low-pressure steel tank, which is used for storage of hydrogen in a metal alloy based on Ti and $\mathrm{Zr}$. An external liquid heat exchanger is considered in the design of the metal hydride tank. Strength calculations were performed to verify the selected wall thickness of the vessel and the wall thickness of the selected bottom type according to STN EN 13322-2 standard for the implementation of a metal hydride tank in operating conditions.

Keywords: Hydrogen, metal alloy, metal hydride storage, hydrogen storage, strength calculation.

\section{Introduction}

Due to the expanding share of hydrogen technologies, the development of hydrogen storage equipment is also underway. At the same time, the most widely used system is based on high-pressure storage, and from a safety point of view, this method may not always be the most appropriate. With the gradual development of low-pressure hydrogen storage in metal alloys, there is a need to design suitable storage vessels that meet the required operational criteria. The main obstacle of lowpressure vessels is the need to cool the alloys during hydrogen absorption and to heat the alloys during desorption.

The design of the tank must be based on the standard STN EN 13322-2, which is given for transport gas cylinders, design and production of refillable steel gas cylinders. The construction consists of the main body of the pressure vessel and a case for the flow of cooling and heating fluid as can be seen in Figure 1.

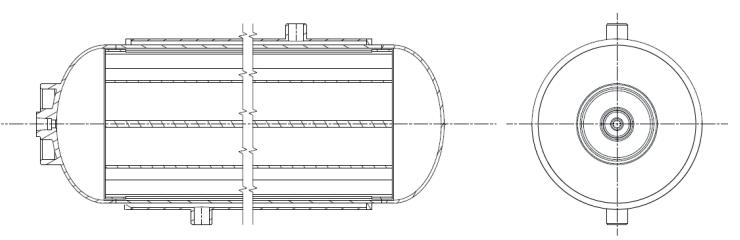

Figure 1. Design of the pressure vessel

Stainless steel 1.4404/316L with the parameters shown in Table 1 was chosen for the construction of the vessel.

Table 1. Mechanical properties of stainless steel 1.4404

\begin{tabular}{|l|l|l|l|l|}
\hline $\mathbf{0 , 2} \% \operatorname{Re}(\mathrm{MPa})$ & $\mathbf{R g}(\mathrm{MPa})$ & $\boldsymbol{\rho}\left(\mathbf{k g} \cdot \mathbf{m}^{-3}\right)$ & $\boldsymbol{\mu}$ & $\mathbf{E}(\mathrm{MPa})$ \\
\hline 200 & $500-700$ & 8000 & 0.3 & $2.1 \cdot 105$ \\
\hline
\end{tabular}

Where Re-yield strength, Rg-ultimate strength, $\rho$-density, $\mu$-Poisson's ratio and E-Young's modulus of elasticity. 


\section{Design of the pressure vessel}

\subsection{Cylindrical wall thickness calculation}

The wall thickness of the cylindrical shell must not be less than that calculated using the formula:

$$
a=\frac{D}{2} \cdot\left(1-\sqrt{\frac{10 \cdot F \cdot J \cdot R_{e}-\sqrt{3} \cdot p_{h}}{10 \cdot F \cdot J \cdot R_{e}}}\right)
$$

where $a$-calculated minimum thickness of the cylindrical shell (mm), $F$ - design stress factor (with a value of 0.77 ), $J$ - stress reduction factor (with a value of 1), $R e$ - yield strength of the used material (MPa), $p h$ - hydraulic pressure above atmospheric.

A diameter $D$ of $159 \mathrm{~mm}$ was considered. According to appendix A in STN EN 13322-2 standard, the value for the stress reduction factor $J$ is 1 , because a butt weld of the closure is considered. According to the standard, the value for the design stress factor $F$ is 0.77 .

$$
\begin{aligned}
& J=1 \\
& F=0.77
\end{aligned}
$$

The value of the $R e / R g$ ratio (where $R e$ - yield strength value determined by the manufacturer and $R g$ - ultimate strength value determined by the manufacturer) shall not exceed 0,85. For calculation, the yield strength in the standard STN EN 13322-2 is limited to a maximum of $0.85 \cdot R g$. Material 1.4404 is considered and the values of $R e$ and $R g$ are:

$$
\begin{aligned}
& R e=0.85 \cdot R g=425 \mathrm{MPa} \\
& R g=500 \mathrm{MPa}
\end{aligned}
$$

The value of the ratio of yield strength to ultimate strength is equal to 0.85 and does not exceed 0.85 , which satisfies mentioned criteria.

$$
\frac{R e}{R g}=0.85
$$

The test hydraulic pressure $p h$ above atmospheric is considered to be $47 \mathrm{bar}$. This value represents the maximum test pressure obtained by the standard STN EN 13445-5. Standard hydraulic test, which states that the maximum test pressure must not be less than the value derived from the relation:

$$
p_{h}=1.43 \cdot p_{t}
$$

where $p t$ represents an operating pressure of 30 bar. After substituting the operating pressure into the
(7):

$p_{h}=42.9 \mathrm{bar}$

Ultimately, a higher value of test pressure $p h$ $=47$ bar was chosen. After substituting to (1) the calculated minimum thickness of cylindrical shell is $\mathrm{a}=1 \mathrm{~mm}$.

\subsection{Design of the bottoms}

To close the vessel, the standard prescribes two types of bottoms, torispherical and ellipsoidal. The shape of the bottoms must meet the following conditions.

For torispherical bottoms:

$R \leq D$

$r \leq 0.1 \cdot D$

$h \geq 4 \cdot b$

For ellipsoidal bottoms:

$H \geq 0.192 \cdot D$

$h \geq 4 \cdot b$

where $R$ - inner radius of the bottom ( $\mathrm{mm}), D$ - outer diameter of the vessel $(\mathrm{mm}), r$ - inner radius of the rounded bottom, $h$ - height of the cylindrical part of the bottom $(\mathrm{mm}), b$ - calculated minimum thickness of cylindrical bottom ( $\mathrm{mm}), \mathrm{H}$ - outer height of the bottom (mm).
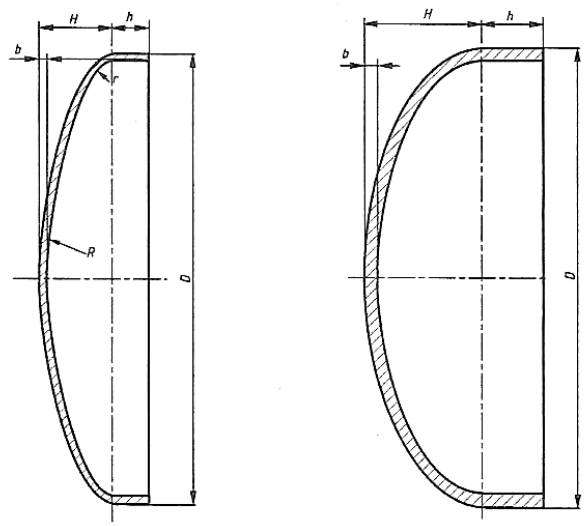

Figure 2. Torispherical and ellipsoidal bottoms

In the case of bottoms, the ellipsoidal bottom type was considered:

$H \geq 30 \mathrm{~mm}$

The value of the outer height of the bottom was chosen to be $50 \mathrm{~mm}$. 
$H=50 \mathrm{~mm}$

The wall thickness of the bottoms of vessels must not be less than the thickness calculated using the formula:

$b=a \cdot C$

where $b$-calculated minimum thickness of the cylindrical bottom ( $\mathrm{mm}$ ), $C$ - shape coefficient of the bottoms (Figure 3).

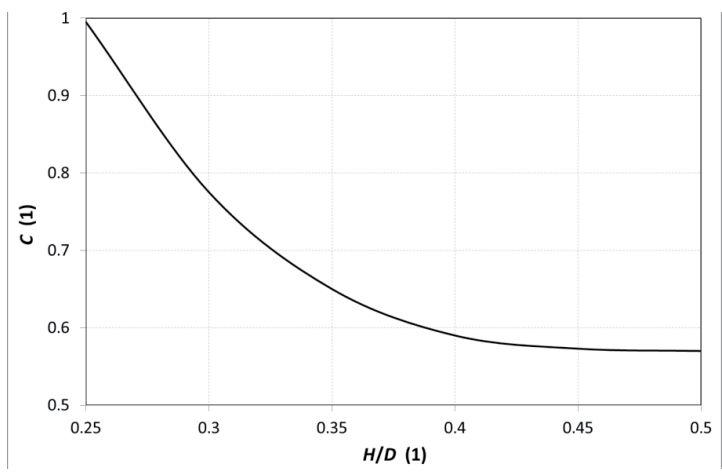

Figure 3. Function of the shape coefficient of the bottoms

The shape coefficient $C$ is obtained by ratio of $H / D$ which is 0.32 .

According to the standard, the value of shape coefficient is 0.7 .

After substituting shape coefficient to (16), the calculated minimum thickness of the cylindrical bottom is obtained $b=0.7$.

After substituting the calculated minimum thickness of the cylindrical bottom to (12), the height of the cylindrical part of the bottom is obtained $b \geq 2.8 \mathrm{~mm}$, whereby the chosen value is:

$$
b=12 \mathrm{~mm}
$$

\subsection{Minimum wall thickness}

In addition to equations (1) and (16), the minimum wall thickness of the cylindrical part and bottom shall not be less than the value derived from any of the following formulas:

$$
\begin{aligned}
& D \leq 100, a=b=1.1 \mathrm{~mm} \\
& 100<D<150, a=b=1.1+0.008(D-100) \\
& D \geq 150, a=b=\frac{D}{250}+0.7 \\
& \text { with absolute minimum of } 1.5 \mathrm{~mm}
\end{aligned}
$$

Since a diameter greater than $150 \mathrm{~mm}$ is considered, than (20) is valid. After substituting the outer diameter of the vessel into the equation (20), the minimum thickness of 1.324 is obtained, so the absolute minimum thickness of the cylindrical part and the bottom is $1.5 \mathrm{~mm}$.

It is based on standard 13322-2 that the construction of bottles may consist of seamless or longitudinally welded tubes. In the case of the proposed vessel, a seamless tube of the cylindrical part of the primary pressure vessel is considered.

The selected dimensions of the thicknesses $a$ thickness of the cylindrical part of the casing and $b$ - thickness of the cylindrical bottom ae: $a=4.5 \mathrm{~mm}$ $\mathrm{a} b=3 \mathrm{~mm}$.

\section{Design of the case for vessel}

\subsection{Cylindrical wall thickness calculation}

A similar design methodology as in Chapter 1 was used to calculate the cylindrical wall thickness.

All values in equation (1) are the same except for the diameter of the cylindrical part $D$, which in this case is $168.3 \mathrm{~mm}$, and the hydraulic pressure above atmospheric ph. which reaches a value of 5 bar. This means that the calculated value of the minimum cylindrical wall thickness of the case is $a=0.15 \mathrm{~mm}$.

The design does not consider the use of bottoms, but only flanges (Figure 4), of which inner diameter is the same as the outer diameter of the primary pressure vessel.

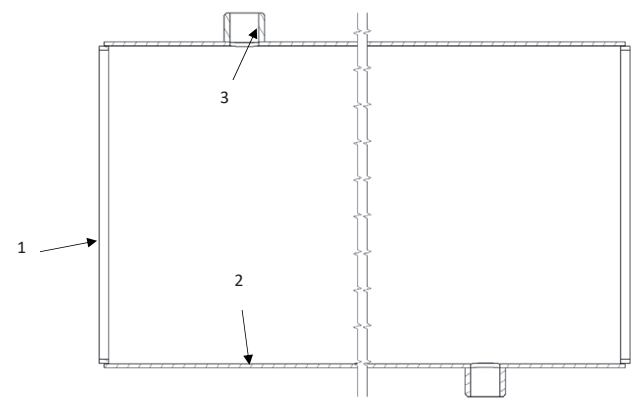

where: 1 - flange, 2 - cylindrical part of the case, 3 - Flange with $\mathrm{G} 1 / 2$ thread

Figure 4. Construction design of the case for the metal hydride vessel

\subsection{Minimum wall thickness}

Together with the equation (1), the minimum thickness must not be less than the value derived from the equation (21). This means that the minimum thickness of the cylindrical part is $1.5 \mathrm{~mm}$. 
There will be one longitudinally welded cylindrical part of the case in the construction, which is an accessory according to the standard STN EN 13322-2. Each accessory must be made of steel compatible with the steel of the vessel. Each accessory is designed to allow inspection of welds according to the standard STN EN 13322-2. There must not be more than one longitudinal joint.

The selected cylindrical wall thickness of the case of hydride container is $a 2=2 \mathrm{~mm}$.

Table 2: Selected dimensions of thicknesses and bottoms

\begin{tabular}{|l|l|l|l|l|l|}
\hline & $a(\mathrm{~mm})$ & $b(\mathrm{~mm})$ & $a 2(\mathrm{~mm})$ & $h(\mathrm{~mm})$ & $H(\mathrm{~mm})$ \\
\hline $\begin{array}{l}\text { Selected } \\
\text { dimensions }\end{array}$ & 4.5 & 3 & 2 & 12 & 50 \\
\hline
\end{tabular}

\section{Verificatory strength calculation by FEM method}

The strength calculation of the vessel was performed in the ANSYS Static Structural program. At the beginning of the simulation, it is necessary to define the boundary conditions and determine the material properties for the pressure vessel.

The mesh consists of 200000 finite elements and 500000 nodes. The material used for the vessel was 1.4404 steel. The boundary conditions applied to the model are:

"The force acting on the wall surface of the vessel arising from the weight of the powdered metal hydride was replaced by the equivalent hydrostatic pressure action of a fictitious liquid with the same density $\mathbf{0}=7000 \mathrm{~kg} \cdot \mathrm{m}^{-3}$.

"Internal surface pressure with magnitude of 4.7 MPa was considered.

"A pressure of $0.5 \mathrm{MPa}$ in the interspace between the primary vessel and the case was considered.

"At the same time, a boundary condition with hydrostatic pressure is applied to surfaces that are in contact with cooling water.

"Standard Earth gravity was applied on the model.

" Cylindrical bond with length of $20 \mathrm{~mm}$ and diameter of the size of the pressure vessel $159 \mathrm{~mm}$ represented by blue colour (Figure 5.) at both ends of vessel was considered. The bond near the outlet has radial and axial displacements removed and the bond at the closed end of the vessel has degrees of freedom removed only in the radial direction.

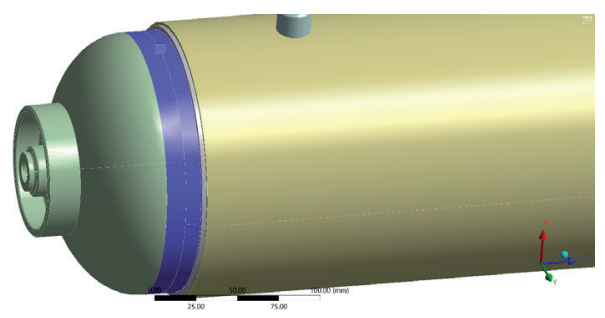

Figure 5. Applied cylindrical bonds

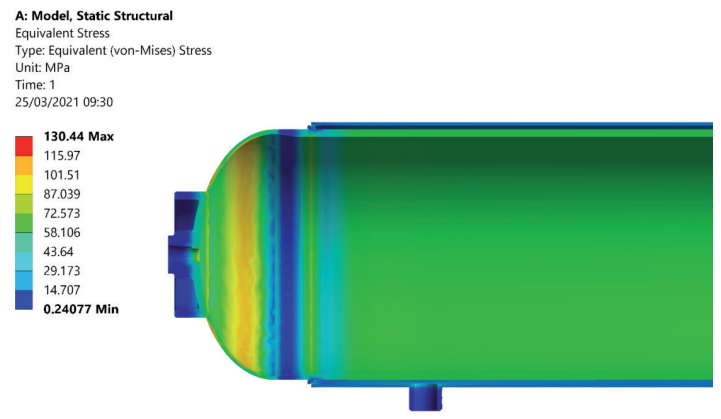

Figure 6. Field of equivalent stresses according to Von-Mises theory (MPa)

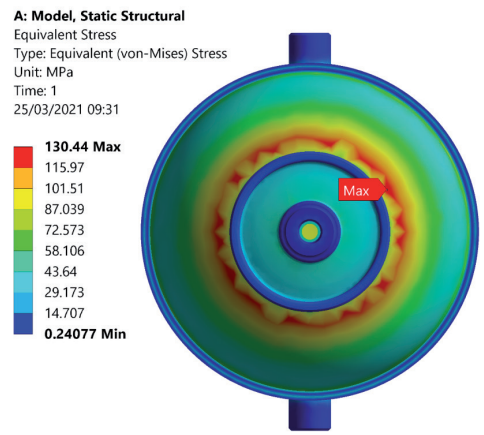

Figure 7. Field of equivalent stresses according to Von-Mises theory-detailed view (MPa)

Table 3: Displacement and stress results

\begin{tabular}{|l|l|}
\hline Total displacement $(\mathrm{mm})$ & 0.09 \\
\hline Directional displacement y $(\mathrm{mm})$ & 0.07 \\
\hline Directional displacement x (mm) & 0.02 \\
\hline Equivalent Von-Mises stress (MPa) & 130.4 \\
\hline
\end{tabular}

The resulting stress is less than yield strength of selected material and thus the design of metal hydride pressure vessel is suitable. 


\section{Conclusion}

The simulations in the Ansys static structural program showed that the vessel, which was designed according to the standard STN EN 133222, meets the requirements for operating parameters of hydrogen storage in metal alloys. With the help of simulations, the shape of the selected bottom was also verified according to the standard for compressive load and production requirements. Using simulation, the selected wall thicknesses of the structure were verified to support the strength of the vessel in their storage. As a result of the combination of the strength analysis and STN EN 13322-2, the ideal wall thicknesses of the pressure vessel were selected, with regard to the required structural strength.

\section{Acknowlegement}

"This contribution was done with the financial support of the grant agency VEGA within the solution of project no. 1/0108/19 and project no. 1/0626/20 and the grant agency KEGA within the solution of the project no. 005TUKE-4/2019."

\section{References}

[1] STN EN 13322-2, Prepravné flaše na plyny. Navrhovanie a výroba znovuplniteliných ocelových fliaš na plyny. Čast' 2: Nehrdzavejúce ocele, 2003

[2] Murín, Justín; Hrabovský, Juraj; Kutiš, Vladimír. Metóda Konečných Prvkov Vybrané kapitoly pre mechatronikov, Slovenská technická univerzita v Bratislave, 2014

[3] Bocko, Jozef; Lengvarský, Pavol; Huňady, Róbert; Delyová, Ingrid. Simulácia $\vee$ programe ANSYS. Stojnícka fakulta, Technická Univerzita v Košiciach, 2020

[4] COMMUNICATION FROM COMMISION TO THE EUROPEAN PARLIAMENT, THE COUNCIL, THE EUROPEAN PARLIAMENT, THE COUNCIL, THE EUROPEAN ECONOMIC AND SOCIAL COMMITTEE AND THE COMMITTEE OF THE REGIONS. A hydrogen strategy for a climate-neutral Europe, Brussels, 2020.

[5] Lotosky, Mykhailo; Tolj, Ivan; Klochko, Yevgeniy; Wafeeg Davids, Moegamat; Swanepoel, Dana; Linkov, Vladimir. Metal hydride hydrogen storage for fuel cell utility vehicles, HySA Systems Competence Centre, South African Institute for advanced Materials Chemistry, 2019.
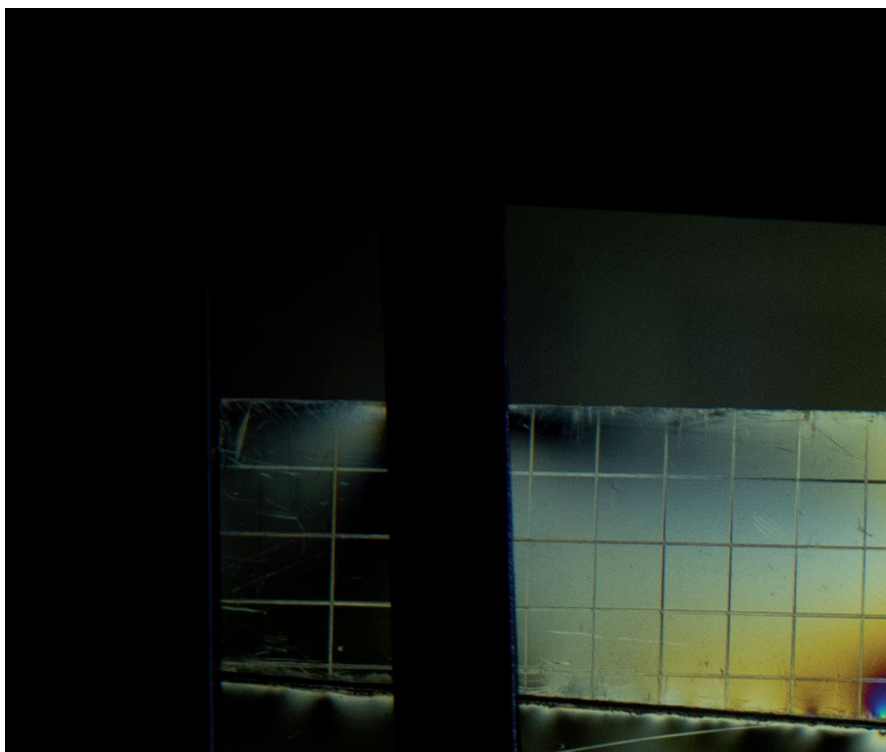